\title{
On the Application of Computer Multimedia in Teaching
}

\author{
Jian Peng
}

Jiangxi Vocational Technical College of Industry \& Trade, Nanchang, Jiangxi, China, 330038

3107000933@qq.com

\begin{abstract}
With the progress of computer technology and the wide use of multimedia in the field of education and teaching, teachers must also have a certain ability to apply multimedia technology, through the application of multimedia technology in education and teaching, can improve the quality and efficiency of education and teaching, but also to stimulate students' interest in learning to a greater extent. This paper mainly focuses on the production of multimedia courseware and the embodiment of computer multimedia teaching methods in teaching links.
\end{abstract}

Keywords: Computer, Multimedia technology, Teaching, Multimedia teaching

\section{论计算机多媒体在教学中的应用}

\author{
彭健
}

江西工业贸易职业技术学院，南昌，江西，中国，330038

3107000933@qq.com

\section{摘要}

随着计算机技术的进步，以及多媒体在教育教学行业的广泛使用，教师也必须要具备一定的多媒体技 术应用能力, 通过在教育教学中应用多媒体技术, 能够提高教育教学的质量和效率, 也能够在更大程 度上激发学生的学习兴趣。而本文就主要围绕多媒体课件的制作以及计算机多媒体教学方法在教学环 节中的体现进行探讨。

关键词: 计算机; 多媒体技术; 教学; 多媒体教学

\section{1. 教学中使用多媒体技术的必要性}

人们现今已然步入了信息时代，而在信息时代，信 息技术成为了人们生活中的不可或缺的存在, 信息技术 不仅在人们的日常生活中为人们提供了很多便利, 使人 们的生活更加便捷, 计算机在各行各业以及教育教学领 域也发挥了其独特的作用, 而由于计算机的出现, 也有 各种各样的软件和计算机技术出现在人们的眼前, 人们 通过这些软件和计算机技术打造出了一个别具一格的 时代, 在这个时代, 人们可以共享教育教学资源, 并通 过共享教育教学资源尽可能的平衡各个地区的教育资 源, 因此换言之, 计算机技术为人们带来了翻天覆地的 改变, 同时也使人们的一切想象都有可能成真。而本文 主要阐述多媒体技术为教育教学所带来的改变和帮助, 在传统的教育教学模式中, 虽然学生能够得到一定的提 升和完善, 但是也会因此而受到一定的限制, 并且传统 教育教学模式有其无法磨灭的弊端。而通过多媒体技术 的应用, 能够使传统教育教学课堂也变得更加和谐活 跃, 学生的思维能够得到充分的发散, 而教师也能够从 教学的主导者转化为引导者。而多媒体技术也能够为学 生们展现更多不一样的色彩, 让学生们即使足不出户,
也能够感受到世界的奇妙, 因此这样也使学生对学习产 生了更加浓厚的兴趣, 虽然人们对于多媒体技术的应用 还有一定的生疏, 但是学校和教师都要勇于迎接这次的 挑战, 勇于做出改变。不同教师的教育教学水平和教师 专业能力有一定差距, 但是脱去传统教育教学的外壳, 教师之间的差距开始变得不那么醒目。至少就目前而 言，教师们站在了同一起跑线，只有能够灵活运用多媒 体技术的教师才能够在专业能力上显现出与其他教师 明显的差别。只要教师能够突破这次的教学困境, 勇于 改变自己的教育教学理念, 并掌握最先进的多媒体技 术, 就会开创一个新的教育教学时代。

\section{表 1 高校教师必须提高自己的专业技能}

\begin{tabular}{|l|l|}
\hline 多媒体技术为教育教 & 多媒体技术也能够为学生 \\
学所带来的改变和帮 & 们展现更多不一样的色 \\
助, 在传统的教育教学 & 彩, 让学生们即使足不出 \\
模式中, 虽然学生能够 & 户, 也能够感受到世界的 \\
得到一定的提升和完 & 奇妙, 因此这样也使学生 \\
善, 但是也会因此而受 & 对学习产生了更加浓厚的 \\
到一定的限制, 并且传 & 兴趣, 虽然人们对于多媒 \\
统教育教学模式有其 & 体技术的应用还有一定的 \\
无法磨灭的弊端。而通 & 生疏, 但是学校和教师都 \\
过多媒体技术的应用, & 要勇于迎接这次的挑战, \\
\hline
\end{tabular}


能够使传统教育教学 课堂也变得更加和谐 活跃, 学生的思维能够 得到充分的发散, 而教 师也能够从教学的主 导者转化为引导者。

\section{2. 多媒体教学的背景}

\section{1. 多媒体教学的意义}

多媒体是一种利用多媒体载体把文本、图像、视频、 声音等信息结合在一起, 并通过计算机进行处理和控制 的一种信息技术。多媒体技术的发展有助于我国信息领 域的发展。在我国高等教育教学上, 多媒体教学可以在 教学过程中为学生提供精彩的图像、优美的文字集成一 体的教学信息, 又能为学生提供多样化的学习方式。

多媒体教学不仅可以为老师在教学过程中提供多 样的功能性, 还能够为学生在学习的过程中提供多样化 的学习方式。同时, 它可以将学生学习的信息反馈到老 师那里, 并且也可以对学生的学习效率进行检验, 可以 通过反馈回来的信息对学生进行教学计划调整, 以及学 生可以通过检验结果及时调整学习方法, 并为学生提供 具有多样性以及创造性的学习环境。在高校教学过程当 中, 教师一般是充当着一个引导人的角色, 教学主要是 以学生为主体。因为这样就可以充分的使学生在学习过 程中激发他们的学习兴趣, 提高他们学习的积极性。由 于学生们的性格特点不一样, 所以学生的学习方式也会 有所不同, 教师可以让学生针对自身的特点来明确自己 的学习目标和学习内容, 并且选择适合自己的学习路 径。然后教师可以通过多媒体信息的反馈来评价学生的 学习。最后针对学生在学习的过程中优、缺点进行总结, 帮助学生可以找到更好的学习方式。

在我国的高等教育教学当中, 计算机多媒体已经被 我国高校普遍应用, 并且计算机多媒体教育已成为我国 高校教学当中的核心技术。

在传统的教学当中, 教师都是通过文本形式向学生 进行人物、景色以及大自然的描述, 而这些通过文字形 式的表达, 让学生无法感同身受, 并且让学生时常感到 枯燥乏味, 然而多媒体却能克服这种现象, 因为多媒体 的运用可以为学生提供形象生动、丰富多彩, 具有较强 感染力的图像, 使学生能够亲眼看见事物的发展状况, 从而流露出真情实感。

\section{2. 多媒体教学中存在的弊端}

事物都有两面性, 多媒体教学既能帮助学生更好的 学习, 同时也存在着一些弊端, 主要表现如下所示:

(1) 不利于学生巩固学习内容

由于多媒体信息容量过大, 所以高校在利用多媒体
教学的方式对学生进行教学的过程当中, 会导致学生在 学习的过程当中加大了课堂的信息容量, 同时也使教学 的进度加快了，导致学生在学习的过程中，不能有效的 巩固学习的内容, 以及对于后续的课程学习无法跟进, 最终让学生的学习效果适得其反。所以高校应该对学生 教学进行合理的教学计划, 让学生在学习的过程中能够 充分体会到多媒体教学的作用之外还能够更好的巩固 学习内容是高校在进行多媒体教学过程当中急需要解 决的问题。

（2）教师教学风格不明显

一个优秀的教师在对学生进行教学的过程当中往 往都会利用一些优美的文字以及生动的肢体语言来向 学生表达教学内容, 从而激发学生的学习兴趣, 在多媒 体教学当中, 由于多媒体涵盖了所有的知识内容, 因此 教师一般会根据自己提前做好的课件进行讲课, 然后在 讲课的过程中也只是照着多媒体读，从而使课堂氛围过 于沉默、教课形式过于呆板、不够灵活, 使学生在学习 的过程中表现得十分被动。

（3）师生互动不够

在多媒体教学的过程当中，一般教师与学生之间没 有什么互动, 很容易造成学生被动的跟着多媒体走, 导 致学生在学习过程中缺乏想象能力, 以及容易分散学生 的注意力, 所以多媒体教学对于学生的情感培养以及想 象能力等方面的效果相对来说较差, 并且还会对学生的 学习产生消极的影响。

\section{3. 多媒体教学方法的合理应用与教学环节设 计}

\section{1. 多媒体教学设计}

通过多媒体技术进行教学设计, 首先就应该对多媒 体技术的运用有一定的了解, 并制定教学计划, 按照教 学目标和教学重难点来进行一定的调整。同时教师还应 该选择教学信息的呈现方式, 教学信息呈现方式不同, 也能够带给学生不同的感受, 多媒体教学设计中需要考 虑到的问题有很多, 例如教学的主要目的和教学任务以 及教学的难点。而学生作为一个不确定性因素, 很容易 给教学效率带来不同程度的影响, 因此教师在进行多媒 体教学设计时，应该考虑到学生这个因素。

\section{2. 多媒体教学方法}

多媒体教学手段只是课堂教学中的辅助手段, 因此 教师在课堂教学中应用多媒体教育手段也应该考虑到 这一点。并不是所有的教学内容都适用于多媒体教学手 段, 教师也应该根据不同的教学内容和不同的教学目 的, 来选择不同的多媒体教学方法。而多媒体教学方法 的差异在不同的学科之间展现的最为明显, 因为不同的 学科的教学内容以及教学目的都存在差异, 所以是即使 
是使用同样的多媒体教学方法, 也可能会呈现出不同的 教学效果。但是毫无疑问的是多媒体教学方法能够充分 的调动学生的积极性, 并培养学生的创新思维, 同时还 能够引导学生对知识进行不断的探索。教师要在课堂教 学中应用多媒体教学技术, 那么就不能将多媒体教学技 术当做课堂的主体。甚至只是制作好多媒体教学课件, 然后在课堂上播放一遍课件就当做完成教学任务。教师 才是知识的主要传授者, 所以教师需要做的只是利用多 媒体教学技术更好地完成教学目标。

\section{3. 多媒体教学环节设计}

在设计多媒体教学方法和教学环节的过程中, 教师 也要考虑到对学生的各方面能力的培养以及对学生思 维能力的锻炼, 因此在其中增添更多的启发性问题, 引 导学生对问题进行思索, 当学生对知识产生了探索欲 时, 学生就相当于对知识产生了学习兴趣, 而学习兴趣 会带领学生更好地掌握知识, 并提升自己的知识水平。 而教师需要明确的是多媒体技术并不是课堂教学的主 体, 课堂教学的主体永远是学生, 而多媒体技术只是教 师教学的工具, 教师可以通过多媒体技术来调动学生的 感官以及求知欲, 但是不能让多媒体技术成为学生的老 师, 因此在对多媒体教学环节进行设计时, 教师应该充 分凸显出对学生各方面能力的培养, 并通过加强和学生 之间的沟通和交流, 将多媒体技术的作用完全发挥出 来。

\section{表 2 多媒体教学方法的合理应用与教学环节设计}

\begin{tabular}{|c|c|c|}
\hline 多媒体教学设计 & 多媒体教学方法 & $\begin{array}{c}\text { 多媒体教学环节 } \\
\text { 设计 }\end{array}$ \\
\hline $\begin{array}{l}\text { 运用系统论的观 } \\
\text { 点和方法, 依据 } \\
\text { 教学目标, 分析 } \\
\text { 教学中的问题和 } \\
\text { 需要, 确定解决 } \\
\text { 问题的步骤, 选 } \\
\text { 择相应的教学策 } \\
\text { 略, 其中包括确 } \\
\text { 定相应知识点排 } \\
\text { 列顺序, 选择教 } \\
\text { 学媒体, 设计教 } \\
\text { 学环境, 以及虑等。 } \\
\text { 机交体考 }\end{array}$ & $\begin{array}{l}\text { 根据教学目的和 } \\
\text { 内容, 选择恰当 } \\
\text { 的多媒体教学方 } \\
\text { 法。不同的学科 } \\
\text { 特点不同, 同一 } \\
\text { 学科的不同教学 } \\
\text { 单元教学内容不 } \\
\text { 同, 同一堂课中 } \\
\text { 也会有不同的内 } \\
\text { 容和目标要求, } \\
\text { 因而运用多媒体 } \\
\text { 教学方法必须首 } \\
\text { 先根据教学内容 } \\
\text { 和任务选择。 }\end{array}$ & $\begin{array}{l}\text { 体现教师在引导 } \\
\text { 学生思维、挖掘 } \\
\text { 学生内在潜质方 } \\
\text { 面所发挥的主导 } \\
\text { 作用, 通过设计 } \\
\text { 一系列富有启发 } \\
\text { 性问题, 引导学 } \\
\text { 生探索事物发生 } \\
\text { 发展与变化的规 } \\
\text { 律, 达到开发学 } \\
\text { 生智力、培养学 } \\
\text { 生能力的目的。 }\end{array}$ \\
\hline
\end{tabular}

\section{4. 结语}

对于传统教育教学而言, 多媒体技术的出现无疑是 对此形成了巨大的冲击, 而对于教师而言, 多媒体技术 的出现也是一个非常大的挑战, 但是只有勇于迎接这次 挑战, 并勇于改变和创新, 教育教学的发展才能够得到 进一步的推动。对于教师而言, 多媒体技术的出现使教 学焕然一新, 也使教育教学的有效性能够得到一定的提
升，而对于学生而言，多媒体技术的出现，让学生能够 更加深刻的感受到知识的趣味性, 同时多媒体有其独特 的作用和优势, 能够化解复杂的知识, 让学生更加直观 清晰的理解知识, 掌握知识。也由于多媒体技术的出现, 引发了学校和教师对教育教学的思考, 不过运用多媒体 技术进行教学, 也并不是完全没有弊端, 现今的弊端就 是很多教师将多媒体技术当作教学的主体, 导致多媒体 技术完全代替了教师。不过相信在一次又一次的实践 中, 教师最终能够掌握最恰当的多媒体技术的应用方 式。

\section{REFERENCES}

[1] Yuzhuo Zhong. development and application of multimedia computers [J]. China Computer Education Journal, No.37,1999.

[2] Liu Xiao etc. The present situation and development of multimedia network teaching system [J]. Multimedia World, No.7,1999.

[3] Liang Zhengming. Multimedia teaching network and classroom teaching [J]. China Audio-visual Education, No.3,1998.

[4] Jia Cuihua. The experience of multimedia network teaching [J]. Modern Educational Science, No.4,2009.

[5] Zhang Furong. Try to talk about the role of multimedia technology in classroom teaching [J]. Teaching Instruments and Experiments, S1,2009.

[6] Zheng Leke. Out of the misunderstanding of multimedia teaching to better serve the cause of education [J]. Hua Zhang, No.11,2009. 